\title{
HEREDITORY GINGIVAL FIBROMATOSIS IN A 7-YEAR-OLD GIRL: A CASE REPORT
}

\section{SANDEEP A BAILWAD ${ }^{1}$, NAVIN PATIL ${ }^{2 *}$, SIVAKUMAR NUVULLA ${ }^{3}$, YOGESH CHHAPARWAL ${ }^{4}$, SAURABH KUMAR $^{5}$, BALAJI $0^{2}$, RAHUL KOTIAN ${ }^{6}$, PRAVEEN KUMAR REDDY ${ }^{7}$}

\begin{abstract}
${ }^{1}$ Department of Pediatric Dentistry, MAHSA University, Malaysia. ${ }^{2}$ Department of Pharmacology, Kasturba Medical College, Manipal University, Manipal, Karnataka, India. ${ }^{3}$ Department of Pedodontics, Narayana Dental College, Nellore, Andhra Pradesh, India. ${ }^{4}$ Department of Dentistry, Manipal College of Dental Sciences, Manipal University, Manipal, Karnataka, India. ${ }^{5}$ Department of Pedodontics and Preventive Dentistry, Manipal University, Manipal, Karnataka, India. ${ }^{6}$ Department of Medical Imaging, SOAHS, Manipal University, Manipal, Karnataka, India. ${ }^{7}$ Department of Dentistry, Faculty of Dentistry, SEGi University, Kota Damansara, Malaysia. Email: navin903@gmail.com
\end{abstract}

Received: 16 October 2016, Revised and Accepted: 24 December 2016

\section{ABSTRACT}

This paper presents a case of hereditary gingival fibromatosis, a rarely reported disorder and addresses the complex nature of oral diagnosis, treatment and long-term case management in the hereditary form of recurrent gingival fibromatosis. Case management is discussed in relation to a 7-year-old girl who presented with recurrent, progressive gingival enlargement requiring consecutive periodontal treatment. The initial course of treatment included 4-quadrant gingivectomy with excisional bevel incisions, followed by microscopic examination of the gingivectomy specimens which supported the clinical diagnosis. 1 year later, recurrence of the condition was observed in all quadrants. It is recommended that patients with this condition be monitored closely after gingivectomy so that the treatment requirements of localized areas can be addressed as needed.

Keywords: Heredity, Genome, Phenotype, Chromosome, Autosomal inheritance.

(C) 2017 The Authors. Published by Innovare Academic Sciences Pvt Ltd. This is an open access article under the CC BY license (http://creativecommons. org/licenses/by/4. 0/) DOI: http://dx.doi.org/10.22159/ajpcr.2017.v10i3.15700

\section{INTRODUCTION}

Hereditary gingival fibromatosis, also known as elephantiasis gingivae, hereditary gingival hyperplasia, idiopathic fibromatosis and hypertrophied gingivae, is a rare (1 in 750,000) autosomal dominant hereditary condition characterized by slow, progressive enlargement of the gingivae, affecting both sexes equally. More recently, hearing loss and supernumerary teeth have been associated with hereditary gingival fibromatosis. The condition has also been reported in association with deficiency of growth hormone caused by lack of growth hormone release factor. Exaggerated stippling may be present. Both the mandible and the maxilla may be affected, and the enlargement may be localized or generalized. The typical histologic appearance of the affected tissue includes hyperplastic epithelium with elongated rete ridges extending deeply into the underlying connective tissue $[1,2]$.

This report presents the clinical and histopathological features and the dental management, over a period of 2 -year, of a young patient with hereditary gingival fibromatosis.

\section{CASE REPORT}

A 7-year-old female patient comes with a chief complaint of swollen gums. The patient reported with difficulty in eating, speech, and esthetic concern. The patient's medical history appeared to be noncontributory, on questioning; the patient's father disclosed that he also had a history of gingival enlargement involving, to various extents, the maxilla as well as the mandible. The patient exhibited no signs of hypertrichosis or mental retardation and had no history of epilepsy or intake of medication known to cause gingival overgrowth. Although not aware of the age at onset of the original symptoms, the parents had noticed a delay in the eruption of certain permanent teeth such as the canines. The patient was especially concerned about the "gummy" appearance of her smile (Fig. 1) and the spacing between her maxillary anterior teeth (Fig. 2). Intraoral examination revealed that the patient was in the mixed dentition stage (Fig. 3). The level of oral hygiene was fair, in spite of the reported difficulty of interproximal flossing, caused by the tissue overgrowth. The maxillary and mandibular dental arches showed generalized gingival fibromatosis affecting both the vestibular and lingual-palatal surfaces. The gingival enlargement was most evident in the maxillary and mandibular anterior regions. Maxillary vestibular and palatal gingivectomy, with excisional bevel incisions, was performed from first molar to central incisor (teeth 16-11), under local anesthesia, to obtain a smoother gingival contour. A biopsy sample of the gingival tissues was submitted for histologic evaluation.

A post-operative dressing was applied. A month later, a similar procedure was performed for the other quadrants. A $0.12 \%$ chlorhexidine gluconate rinse was prescribed for administration twice a day for 2 weeks. The patient was seen at 1,3 , and 5 weeks postoperatively. Postsurgical healing was uneventful and because the patient's oral hygiene was fair, supportive periodontal therapy was initiated. $1 \frac{1}{2}$ years later, the patient exhibited recurrence of the fibromatosis in all 4 quadrants. The condition was particularly prominent in the anterior palate, the maxillary and mandibular anterior labial regions, and the mandibular posterior buccal regions. The appearance of the tissues was very similar to that seen at the original presentation. Accordingly, another gingivectomy procedure is been planned.

\section{Histopathology}

Microscopic examination of the specimens confirmed that the general appearance of the lesion was consistent with that described previously for hereditary gingival hyperplasia: Abundant, dense connective tissue in which markedly thickened fiber bundles alternated with relatively finer collagen fascicles, the fiber bundles being speckled with small, dark fusiform nuclei of fibroblastic cells with scanty cytoplasm, plump fibroblasts were seen only focally. Neurovascular bundles were well represented, but sparsely distributed neuronal axons (typical of neurofibroma) and palisading or streaming of cells (typical of neuromas or neurilemomas) was not observed in the tissues. The surface epithelium was characteristically hyperplastic, exhibiting a pseudoepitheliomatous appearance (Fig. 4). 


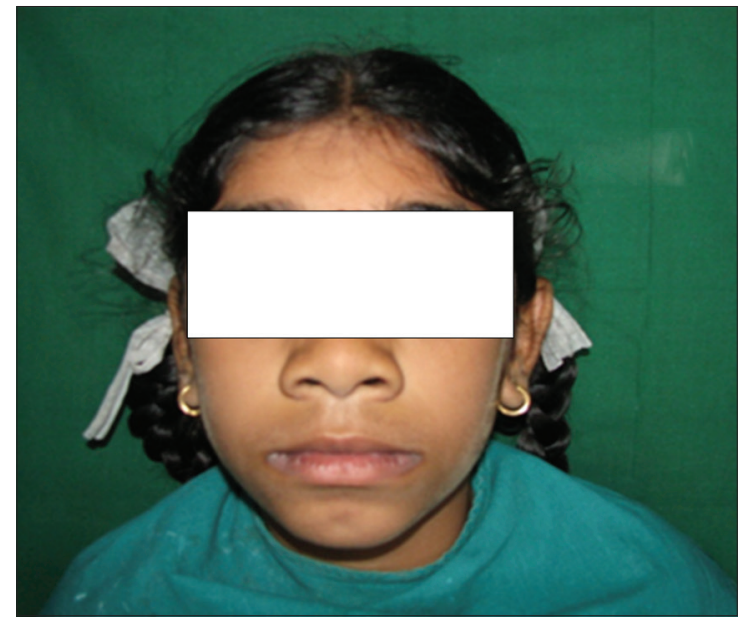

Fig. 1: Facial profile of the patient

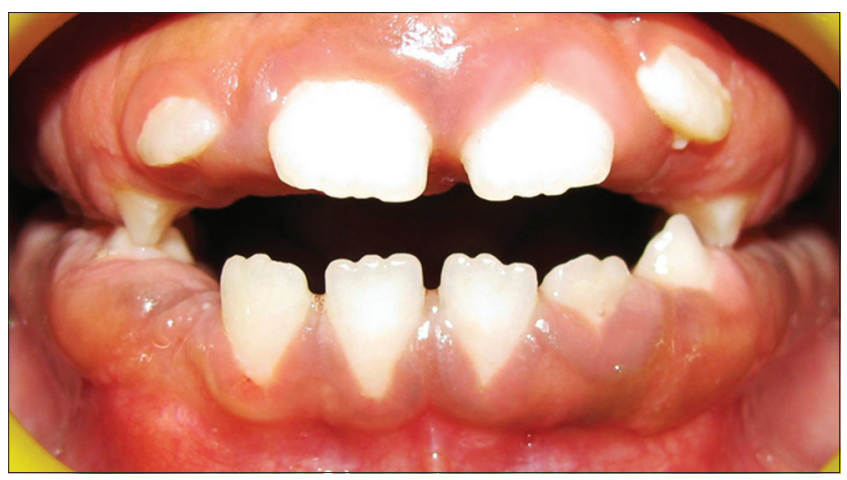

Fig. 2: Intraoral view of maxilla and mandible showing the presence excessive gingival overgrowth

\section{DISCUSSION}

The presented case was diagnosed as hereditary gingival fibromatosis based on the patient's history, clinical and histopathological examination. Since the recurrence was observed it can be concluded that although many advances have taken place in the field of dentistry only symptomatic relief can be provided to the patient when such type of cases are encountered. The mode of genetic transmission in this patient points to an autosomal recessive gene because only father was affected and the condition was present in successive generation. In this case, the patient did not exhibit any signs or symptoms suggesting that the condition was syndromic. The diagnosis was made on the basis of the clinical presentation, the family history and the pattern of recurrence and the characteristic microscopic features of the histology samples. There is inconsistency in the literature as to the cellular and molecular mechanisms that lead to this condition. Some authors report an increase in the proliferation of gingival fibroblasts, whereas others report slower than normal growth [3]. According to a recent report increased collagen synthesis rather than decreased levels of collagenase activity may be involved. Hereditary gingival fibromatosis has been predominantly described as a benign condition $[4,5]$. One case of focal epithelial dysplasia arising from the overgrown tissues has been reported but the report did not make clear whether there was any causal relationship between the fibromatosis [1].

\section{CONCLUSION}

This report outlines the diagnosis and treatment of a patient with hereditary gingival fibromatosis. Because this condition is rare,

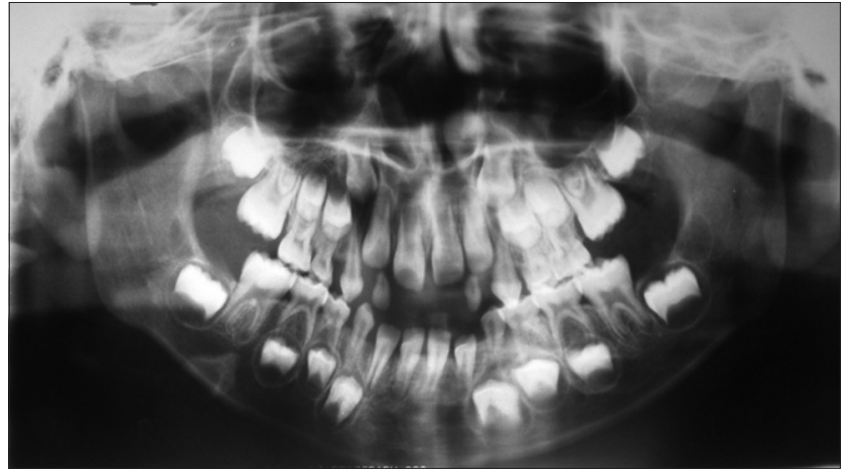

Fig. 3: The orthopantomograph revealed presence of normal permanent tooth buds, improper occlusion, and partially erupted 22,1216 , and 26

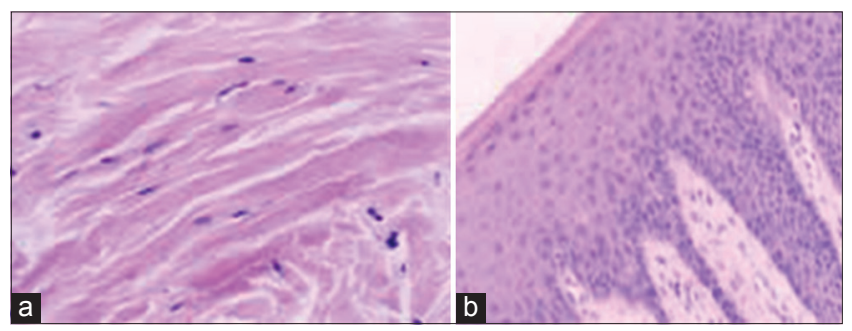

Fig. 4: ( $a$ and $b$ ) The microscopic picture of hereditary gingival fibromatosis

there are only a few case reports addressing its diagnosis, dental management and long-term treatment [6]. This report underlines the role of pedodontist to allow optimal oral hygiene and adequate lip seal during swallowing. Proper tooth repositioning and lip seal prevent mouth-breathing, which might otherwise exacerbate the condition. Past research has focused mostly on the causes of druginduced hyperplasia's [7]. A recent electron microscopic study of samples from patients with hereditary gingival fibromatosis suggests that the distribution of collagen fibers in this form of the condition is distinct from that seen in nonfamilial cases. Recent investigations have yielded new invaluable information on the genetic and molecular mechanisms of gingival overgrowth, but further research is needed to elucidate the etiology and complex pathogenesis of this condition.

\section{REFERENCES}

1. Kelekis-Cholakis A, Wiltshire WA, Birek C. Treatment and long-term follow-up of a patient with hereditary gingival fibromatosis: A case report. J Can Dent Assoc 2002;68(5):290-6.

2. Baptista IP. Hereditary gingival fibromatosis: A case report. J Clin Periodontol 2002;29(9):871-4.

3. Doufexi A, Mina M, Ioannidou E. Gingival overgrowth in children: Epidemiology, pathogenesis, and complications. A literature review. J Periodontol 2005;76(1):3-10.

4. Hart TC, Zhang Y, Gorry MC, Hart PS, Cooper M, Marazita ML, et al. A mutation in the SOS1 gene causes hereditary gingival fibromatosis type 1. Am J Hum Genet 2002;70:943-54.

5. Kavvadia K, Pepelassi E, Alexandridis C, Arkadopoulou A, Polyzois G, Tossios K. Gingival fibromatosis and significant tooth eruption delay in an 11-year-old male: A 30-month follow-up. Int J Paediatr Dent 2005;15(4):294-302.

6. Anegundi RT, Sudha P, Nayak UA, Peter J. Idiopathic gingival fibromatosis: A case report. Hong Kong Dent J 2006;3:53-7.

7. Mavrogiannis M, Ellis JS, Thomason JM, Seymour RA. The management of drug-induced gingival overgrowth. J Clin Periodontol 2006;33(6):434-9. 